This document is the accepted manuscript version of the following article:

Guo, H., Warnicke, P., Griffa, M., Müller, U., Chen, Z., Schaeublin, R., ... Luković, M. (2019). Hierarchical porous wood cellulose scaffold with atomically dispersed Pt catalysts for low-temperature ethylene decomposition. ACS Nano.

https://doi .org/10.1021/acsnano.9b07801

\title{
Hierarchical Porous Wood Cellulose Scaffold with Atomically Dispersed Pt Catalysts for Low-Temperature Ethylene Decomposition
}

Huizhang Guo, ${ }^{* 1,2}$ Peter Warnicke, ${ }^{3}$ Michele Griffa, ${ }^{4}$ Ulrich Müller, ${ }^{5}$ Zupeng Chen, ${ }^{6}$ Robin Schaeublin, ${ }^{7}$ Zhidong Zhang, ${ }^{8}$ Mirko Luković*1,2

\footnotetext{
${ }^{1}$ Wood Materials Science, ETH Zürich, 8093 Zürich, Switzerland.

${ }^{2}$ Cellulose and Wood Materials, Empa - Swiss Federal Laboratories for Materials Science and Technology, 8600 Dübendorf, Switzerland.

${ }^{3}$ Paul Scherrer Institut, 5232 Villigen PSI, Switzerland.

${ }^{4}$ Concrete/Construction Chemistry, Empa - Swiss Federal Laboratories for Materials Science and Technology, 8600 Dübendorf, Switzerland.

${ }^{5}$ Nanoscale Materials Science, Empa - Swiss Federal Laboratories for Materials Science and Technology, 8600 Dübendorf, Switzerland.

${ }^{6}$ Institute for Chemical and Bioengineering, Department of Chemistry and Applied Biosciences, ETH Zürich, Zürich, Switzerland.

${ }^{7}$ ScopeM-Scientific Center for Optical and Electron Microscopy, ETH Zürich, 8093 Zürich, Switzerland.

${ }^{8}$ Durability of Engineering Materials, ETH Zürich, 8093 Zürich, Switzerland.

*Email: huguo@ethz.ch, lukovicm@ifb.baug.ethz.ch
}

\begin{abstract}
Despite the excellent catalytic properties of individual nanoparticles and atomic clusters, the current capabilities to assemble them into a complex system are insufficient for many practical applications. An objective of this work is to develop a fabrication technology that allows for the simultaneous control of the nanoparticle surface chemistry, elemental distribution, microscale geometry, and large-scale assembly. Using a cellulose structure derived from wood, we fabricated hierarchical porous cellulose scaffolds combined with cerium-doped $\mathrm{TiO}_{2}$. This hybrid material served as the support for atomically dispersed Pt catalysts and was used to successfully decompose ethylene at zero degrees Celsius. The fabrication concept developed in this work would allow mitigating the conflict between the required large active surfaces and the difficulties in handling nanopowders in environmental catalysis, including food preservation and indoor air purification. We thus discovered a promising route to manufacture multifunctional materials with complex structures by combining a controllable chemical synthesis with the nature-designed wood scaffold.
\end{abstract}

Keywords: wood cellulose scaffold, environmental catalysis, atomically dispersed Pt, hierarchical porosity, gas transport, ethylene decomposition 
Ethylene $\left(\mathrm{C}_{2} \mathrm{H}_{4}\right)$ is a natural ripening hormone of plants. ${ }^{1} \mathrm{~A}$ small amount of ethylene can accelerate the deterioration of fresh products such as fruits and vegetables. Therefore, it is important to develop atmosphere-controlling technologies that can extend the postharvest life of fresh food shipped over long distances. ${ }^{2}$ Among the existing strategies applied for ethylene elimination, catalytic oxidation of ethylene to carbon dioxide and water is considered to be a promising route. ${ }^{3}$ In this view, heterogeneous photocatalysis has attracted the interest of researchers. ${ }^{3,4}$ Bhattacharyya et al. used vanadium-doped titania as a photocatalyst for gas-phase oxidation of ethylene, which exhibited better performance than nano-titania. Their study demonstrated that ethylene decomposition occurred via the formation of ethoxy groups, which subsequently transformed to acetaldehyde or enolates, then to acetates/formate, and finally, to $\mathrm{CO}_{2}{ }^{5}$ The vanadium-doping enhanced the catalytic activity by forming more chemisorbed hydroxyl species which might have increased the average coverage and residence time of intermediates for further oxidation. ${ }^{6}$

Besides the fundamental understanding of how to improve the turnover frequency of the active sites, the rational design of a nanostructured substrate with higher specific surface area and porosity, which is beneficial to mass transport, is of equal importance. For this reason, $\mathrm{C}_{3} \mathrm{~N}_{4}$ was used as a template for the synthesis of oxygen-deficient, porous $\mathrm{TiO}_{2}$ nanosheets with Pt decoration. A superior photocatalytic performance for ethylene oxidation was obtained thanks to the textural features of $\mathrm{Pt}_{-} \mathrm{TiO}_{2}$ nanosheets, including their narrower bandgap and mesoporous structure. ${ }^{7}$ However, the decomposition of ethylene without a light source is important because most foods are stored in closed and dark spaces. Metal oxide-supported noble metal nanoparticles are state-of-theart catalysts for the complete and direct oxidation of trace ethylene. ${ }^{8,9}$ Mesoporous $\mathrm{Au} / \mathrm{Co}_{3} \mathrm{O}_{4}$ catalysts, synthesized by a casting approach, can achieve a conversion of $76 \%$ of the ethylene at $0{ }^{\circ} \mathrm{C}$ due to the fact that surface-active oxygen species were produced easily by the active sites of nanogold on the porous structure of $\mathrm{Co}_{3} \mathrm{O}_{4} \cdot{ }^{10}$ In spite of this significant improvement, a great effort is still demanded to reach a complete decomposition of trace $(50 \mathrm{ppm})$ ethylene at $0^{\circ} \mathrm{C}$. Fukuoka's group reported that the catalyst prepared by supporting Pt nanoparticles on mesoporous silica MCM-41 had a $99.8 \%$ conversion of $50 \mathrm{ppm}$ ethylene at $0{ }^{\circ} \mathrm{C} .{ }^{11}$ However, the Pt utilization still needs to be improved. A recent study showed that the $\mathrm{CeO}_{2}$ support enhanced the catalytic rate of the metal catalyst due to the influence of the lattice oxygen and oxygen storage capacity of $\mathrm{CeO}_{2}{ }^{12}$ The previous research indicates a catalyst design that would: 1) have suitable doping in the metal oxide support to facilitate the spontaneous back spillover of $\left.\mathrm{O}^{2-} ; 2\right)$ increase the dispersion of the noble metal for a higher utilization efficiency as well as higher activity. 
In addition to the improvement of the catalyst activity, there is an increasing interest in the development of material manufacturing processes to integrate nanostructures in bulk systems for practical applications in indoor air cleaning. The main concern for the application of nano- or micrometer size catalysts in powder form is that they become a source of pollution once released in the air. Therefore, in order to trap the nanoparticles, honeycomb ceramics were used as a support for Pt nanoparticles for formaldehyde decomposition. ${ }^{13}$ In the case of the photocatalytic oxidation of ethylene, glass rings are to date the most investigated type of support. ${ }^{14,15}$ The drawback of these technologies is the limited specific surface area and the low porosity, which results in poor mass transport and interaction with the active species. Moreover, the fabrication process is energy consuming (high-temperature calcination). Although we have seen significant advancements in artificial materials fabrication in the past decades, current technologies are still not capable of producing complex materials with as many integrated functions as those found in nature.

The distinctive qualities of the elegant and complex architectures of natural structures have been a continuous source of fascination and inspiration for scientists and engineers, as they possess a perfect control over the structure, texture, and the functionalization at different scales. ${ }^{16-18}$ Dong et al. used cedar and bamboo as templates to fabricate self-standing zeolitic tissue that inherits the hierarchical cellular structure of the plant tissues at various hierarchical levels. The wood-templated hierarchically porous zeolites offer possibilities of application in catalysis. ${ }^{19,}{ }^{20}$ Wood is mainly composed of elongated cells that are oriented in the longitudinal direction with an empty lumen in the microscale range. ${ }^{21}$ The individual cells are connected through pits. At the ultrastructural level of wood, the cell walls consist of cellulose, hemicellulose, and lignin. Cellulose microfibril aggregates, which are $\sim 20 \mathrm{~nm}$ wide, bind together to form a skeleton, which, surrounded by hemicelluloses and lignin, acts as a matrix. ${ }^{22}$ The hemicelluloses and lignin can be selectively dissolved in strong acid or basic solvents in a so-called delignification process. ${ }^{23}$ Hierarchical porous cellulose scaffolds can be generated via delignification. ${ }^{24}$ We propose to use wood cellulose scaffolds to control the sub-nano Pt cluster assemblies at high concentrations, without undermining their initial functionality and providing the sufficient mechanical integrity for their handling. ${ }^{25-27}$ 


\section{Results and discussion}

Hierarchically porous wood cellulose and $\mathrm{TiO}_{2} / \mathrm{Ce}$ xerogel hybrid materials $(W T i)$ were prepared by combining a controllable chemical synthesis with the natural wood scaffolds. As schematically illustrated in Figure 1, the protocol starts with delignification to obtain a cellulose scaffold which retains the microscale structure and orientation of the wood cellulose fiber, while creating nanoscale porosity in the wood cell wall. ${ }^{23,28}$ The cellulose scaffold was dehydrated via solvent exchange with isopropanol. The condensation of titanium oxide xerogel with cerium doping $\left(\mathrm{TiO}_{2} / \mathrm{Ce}\right.$ xerogel) was adapted from previous work. ${ }^{29}$ According to the precursors' proportion for the preparation of $\mathrm{TiO}_{2} / \mathrm{Ce}$ xerogel, the atomic ratio of $\mathrm{Ti}$ to $\mathrm{Ce}$ was calculated to be $220: 1$. In the presence of the wood cellulose scaffold, the xerogel formed a coating on the surface of cellulose microfibril as the isopropanol evaporated. STEM imaging shows that the freestanding xerogel removed from WTi had the morphology of nanosheets (Figure S4), implying that the $\mathrm{TiO}_{2} / \mathrm{Ce}$ xerogel coats of the cellulose microfibrils surface act as a thin film. According to Thermogravimetric analysis (TGA) measurement (Figure S5), the wood cellulose scaffold has a weight loss of about $100 \%$ in the end, while $W T i$ has a weight loss of $\sim 65.4 \%$. $\mathrm{TiO}_{2} / \mathrm{Ce}$ only has phase change instead of decomposition during the heating up to $800{ }^{\circ} \mathrm{C}$. Therefore, the weight ratio between cellulose and $\mathrm{TiO}_{2} / \mathrm{Ce}$ xerogel of WTi is 64.4:35.6. The TGA analysis also indicates that the wood cellulose scaffold starts to decompose at a temperature higher than $250^{\circ} \mathrm{C}$.

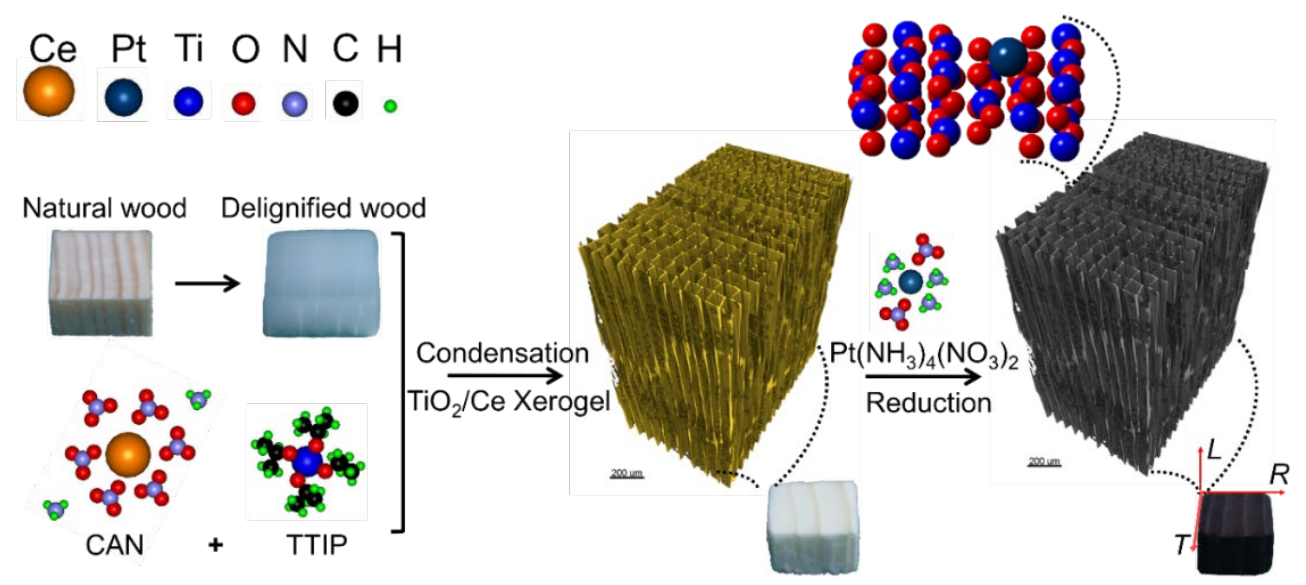

Figure 1. Schematic illustration of the fabrication of atomically dispersed Pt on $W T i$. The fabrication process includes delignification, condensation of $\mathrm{TiO}_{2} / \mathrm{Ce}$ xerogel, loading of platinum precursor and thermal decomposition.

Tetraammineplatinum(II) nitrate $\left(\mathrm{Pt}\left(\mathrm{NH}_{3}\right)_{4}\left(\mathrm{NO}_{3}\right)_{2}, T A P N\right)$ was used as the precursor of Pt, which anchored to the surface of $\mathrm{TiO}_{2} / \mathrm{Ce}$ xerogel after the $W T i$ was soaked in the aqueous solution of 
$T A P N$. The zeta potential of WTi fiber dispersed in water is $-20.3 \pm 3.6 \mathrm{eV}$, which indicates that the surface of WTi in water is negatively charged. Therefore, the cationic Pt complex $\left[\mathrm{Pt}\left(\mathrm{NH}_{3}\right) 4\right]^{2+}$ was anchored to the WTi substrate by electrostatic interaction, which is consistent with previous reports. ${ }^{30}$ The auto-reduction of the $\mathrm{Pt}^{2+}$ complex happened at $250{ }^{\circ} \mathrm{C}$ in $5 \% \mathrm{H}_{2} / 95 \% \mathrm{~N}_{2}$ atmosphere according to what reported in the literature. ${ }^{31}$ The low-temperature auto-reduction suggests an immobile species, which is the key to obtain atomically dispersed Pt. Partially charged isolated Pt atoms were stabilized by forming Pt-O bonds with the substrate. ${ }^{32}$ After the auto-reduction of the impregnated TAPN, the WTi support turned from light yellow to dark. XRD analysis indicated that there was no crystallized Pt or platinum oxide in the as-synthesized samples (Figure S6). The heat treatment of WTi without any $T A P N$ loading at $250{ }^{\circ} \mathrm{C}$ did not change the cellulose crystalline phase. However, such phase was strongly damaged in WTi-Pt2.5 and WTi-Pt10, which may have been due to the attack from the intermediates generated by the decomposition of TAPN.

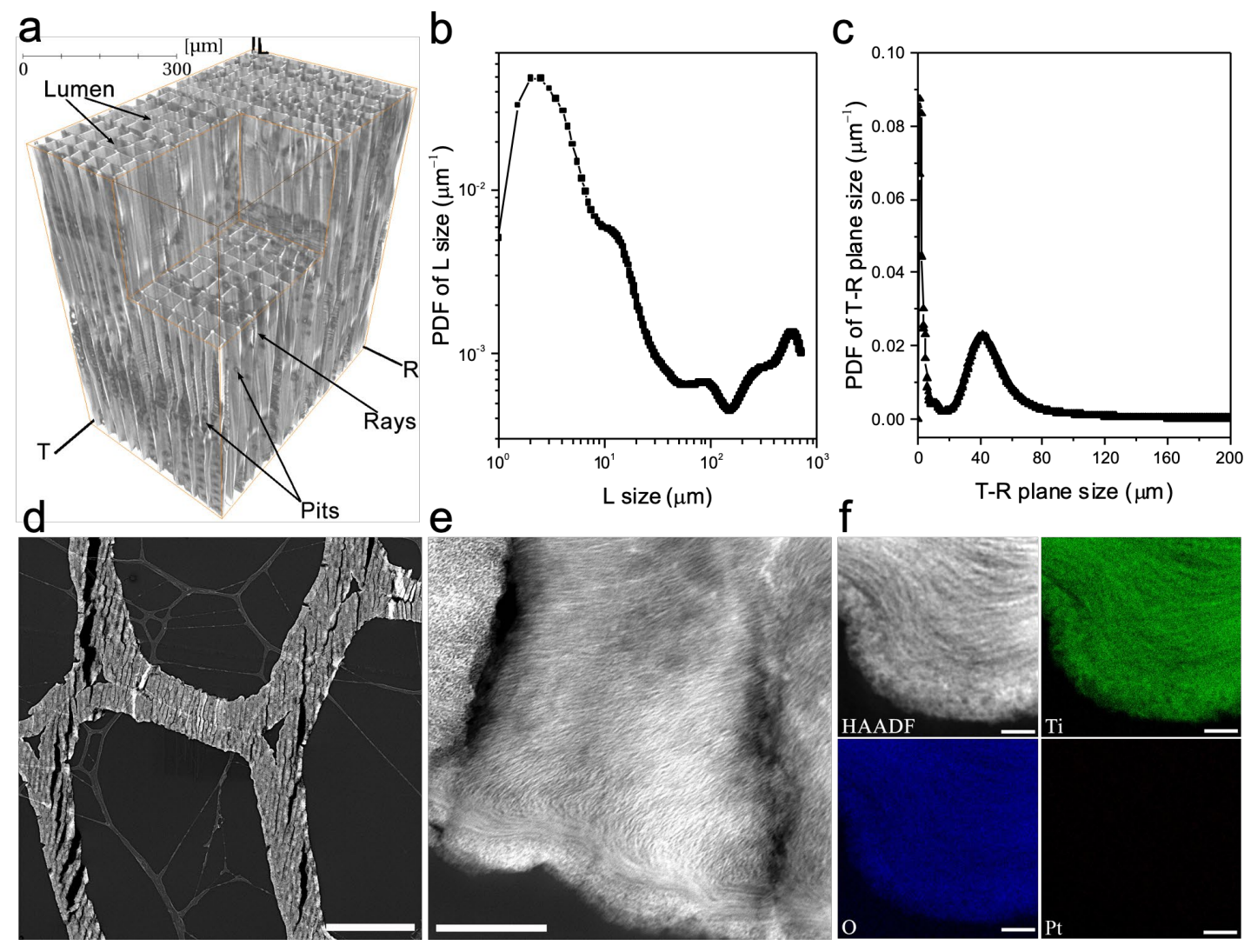

Figure 2. 3D computer graphics rendering of WTi-Pt2.5 (a). Two distinct pore size variables were computed for each distinct and separated pore region: the size approximately along the wood cell's longitudinal direction ("L size", b) and the largest of the sizes along directions approximately lying on the tangential-radial 
plane ("T-R plane" size, c), approximately orthogonal to the longitudinal axis. Low (d) and high (e) magnification HAADF-STEM images of transverse section lamella of WTi-Pt2.5. EDS mapping on the cell wall indicating the distribution of $\mathrm{Ti}, \mathrm{O}$, and $\mathrm{Pt}$ (f). The scale bar in $\mathrm{d}$, e and $\mathrm{f}$ is $5 \mu \mathrm{m}, 200 \mathrm{~nm}$ and $20 \mathrm{~nm}$, respectively.

The hierarchical porosity of $W T i-P t 2.5$ was characterized at distinct length scales using X-ray tomography, $\mathrm{N}_{2}$ aborption-desorption and STEM. The X-ray tomography measurement allowed resolving pore features essentially above $1 \mathrm{um}$. Figure $2 \mathrm{a}$ shows a 3D computer graphics rendering of the same portion of the volume of $W T i-\mathrm{Pt} 2.5$ as used for producing the 3D geometrical model for the lattice Boltzmann simulations of the gas transport process. About one eighth of the entire volume (top-front corner) was not rendered in order to better visualize typical anatomical features of the wood-based scaffold. The cellular structural features of spruce wood, including longitudinal lumens (also called tracheids), radial parenchyma (also called rays) as well as pits connecting the lumens were well preserved at micro-scale (Figure 2a and Movie S1). Figures $2 \mathrm{~b}$ and 2c show the results of a semi-quantitative characterization of the pore space of WTi-Pt2.5 obtained from the analysis of the X-ray tomogram, thus considering only parts of the pore space larger than $1 \mu \mathrm{m}$. Both figures show pore size distributions in the form of plots of the probability distribution function (PDF) of a pore size variable, considered as a random variable. Section 1 of the Supplementary Information provides the details about the 3D image analysis workflow, based upon the shape tensor analysis, used for computing the PDF of each of the two size variables. Along directions on the T-R plane (Figure 2c), one single peak is visible at about $41 \mu \mathrm{m}$. This can be considered as a characteristic cell size in the Tangential-Radial plane, although, as explained in Section 1 of the Supplementary Information, it is a slight overestimation of such characteristic size. Along the L direction (Figure 2b), more than one characteristic size is observed, corresponding to multiple, partly overlapped peaks: one peak is located at about $580 \mu \mathrm{m}$, characteristic of the longest and mostly intact lumens, two other ones are at about 285 and $85 \mu \mathrm{m}$, respectively, while the final is about $11 \mu \mathrm{m}$. Such manifold of characteristic L size values of the wood cells is due to distinct cell types, some of which located close to the boundaries of the measured volume, while others are very regular lumens, or lumens in contact with other types of cells, e.g., rays. For information about why the two reconstructed PDFs plotted in Figure $2 \mathrm{~b}$ and $2 \mathrm{c}$ achieve very large values close to zero, please refer to Section 1 of the Supplementary Information.

The $\mathrm{N}_{2}$ absorption-desorption curves of $W T i$ and $W T i$-Pt2.5 show typical IV isotherms (Figure S7a), according to the International Union of Pure and Applied Chemistry (IUPAC) classification, ${ }^{33}$ an 
indication of the presence of mesoporous pores. A higher surface area and a narrower nanopore size distribution (Figure S7b) were obtained for WTi-Pt2.5 $\left(51.81 \mathrm{~m}^{2} / \mathrm{g}\right)$ than native spruce $(0.33$ $\left.\mathrm{m}^{2} / \mathrm{g}\right)$ and the $W T i\left(33.05 \mathrm{~m}^{2} / \mathrm{g}\right)$. The heat treatment created a large number of nano-scale voids or cracks in the cell wall regions which is consistent with the observation by STEM imaging shown in Figure 2d. The contrast resulting from the orientation of the cellulose microfibrils can be seen in the STEM image as well (Figure 2e). The results indicate that the $\mathrm{TiO}_{2} / \mathrm{Ce}$ xerogel condensed along the cellulose fibrils as a shell, which is in agreement with the previous report by Deshpande et al. ${ }^{23}$ EDS mapping reveals that $\mathrm{Ti}$ and $\mathrm{O}$ were uniformly dispersed in the cell wall region (Figure $2 \mathrm{f}$ ). However, the characteristic X-rays from Pt were not detected by EDS (Figure $2 \mathrm{f}$ and Figure S8) presumably due to the low Pt concentrations, below the EDS detection limit, despite the accumulation on the lumen surfaces that should have locally increased its concentration. ICP-OES determined the average Pt concentration (mass fraction) to be $1.36 \mathrm{ppm}, 6.58 \mathrm{ppm}$ and $11.72 \mathrm{ppm}$
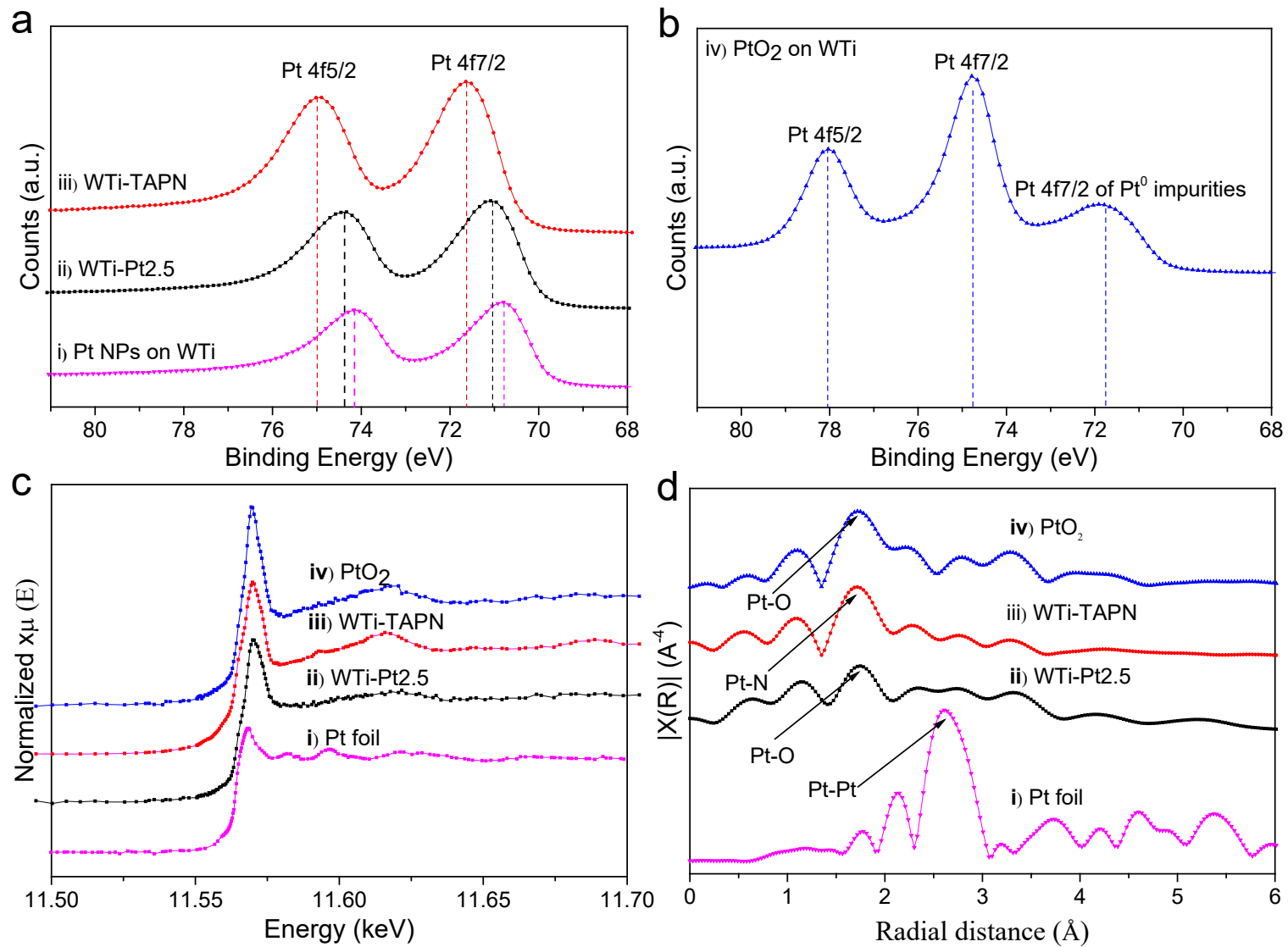

for WTi-Pt1, WTi-Pt2.5 and WTi-Pt10, respectively.

Figure 3. (a) XPS spectra for $W T i$-Pt2.5 together with $T A P N, \mathrm{PtO}_{2}$ and metallic Pt nanoparticles supported on WTi for comparison; (b) XPS spectrum for $\mathrm{PtO}_{2}$ supported on WTi. (b) X-ray absorption fine structure 
spectra for different Pt species supported on WTi; (c) Radial plots obtained from the Fourier transformation of the extended X-ray absorption fine structure oscillations.

The oxidation state of Pt in WTi-Pt2.5 was investigated by X-ray photoelectron spectroscopy (XPS) (Figure 3a). The XPS spectra of TAPN, metallic Pt nanoparticles and $\mathrm{PtO}_{2}$ (Figure 3b) supported on $W T i$ were also provided for comparison. The Pt $4 \mathrm{f}$ spectrum of Pt nanoparticles can be deconvoluted into two peaks at binding energies of 70.8 and $74.1 \mathrm{eV}$, corresponding to the $4 \mathrm{f} 7 / 2$ and 4f5/2 levels, respectively. ${ }^{34}$ In contrast, the XPS spectrum of $\mathrm{PtO}_{2}$ can be deconvoluted into two peaks at binding energies of 74.8 and $78.1 \mathrm{eV}$ due to $\mathrm{Pt}(\mathrm{IV})$ species together with a trace of $\mathrm{Pt}(\mathrm{II})$, which corresponds to the peak at $71.9 \mathrm{eV}$ (Figure $3 \mathrm{~b}$ ). The Pt $4 \mathrm{f}$ spectrum of the TAPN absorbed by the surface of WTi exhibits one doublet with Pt 4f7/2 binding energy of $71.7 \mathrm{eV}$ and Pt 4f5/2 binding energy of $75.0 \mathrm{eV}$, which is characteristic of the $\mathrm{Pt}(\mathrm{II})$ species. ${ }^{35}$ The surface of $\mathrm{TiO}_{2} / \mathrm{Ce}$ xerogel before the heat treatment was highly hydroxylated, which contributed to the uptake and stable binding to the cationic $\mathrm{Pt}\left(\mathrm{NH}_{3}\right){ }_{4}{ }^{2+}$ via electrostatic adsorption. ${ }^{35} \mathrm{WTi}$-Pt2.5 was prepared by heat treatment at $250{ }^{\circ} \mathrm{C}$ in $5 \% \mathrm{H}_{2}$ and $95 \% \mathrm{~N}_{2}$ atmosphere for $2 \mathrm{~h}$, in which the Pt XPS spectrum was not identical with that of $T A P N$ or metallic Pt nanoparticles. A Pt species with binding energies at 71.7 and $74.4 \mathrm{eV}$ was detected, which stayed between $\mathrm{Pt}(\mathrm{II})$ and $\mathrm{Pt}(0)$. This result indicates that the Pt atoms in $W T i-\mathrm{Pt} 2.5$ carried partially positive charge through electron transfer between metal and $\mathrm{TiO}_{2} / \mathrm{Ce}$ xerogel support because of the enhanced metal-support interaction. ${ }^{30,36}$ We used XPS depth profiling to characterize the distribution of Pt element. The results strongly indicate that the Pt atoms mainly located on the cell wall surfaces (Figure S9 and Table S1).

X-ray absorption spectroscopy analysis provides more representative information on the overall structure. To characterize the electronic structure of the specimens, we measured XANES (X-ray absorption near edge structure spectra) at the Pt L3 edge. XANES was measured in fluorescence mode, allowing us to probe the low Pt concentrations present in the samples. XANES is a wellestablished technique for probing the valence state, which can be inferred from the energy shift of the absorption edge. As can be seen in Figure 3b, the metallic Pt reference has the edge located at $11564 \mathrm{eV}$ as expected for zero-valent Pt. In the case of WTi-Pt2.5 and WTi-TAPN (Figure 3c), the edges are shifted by $3 \mathrm{eV}$ indicative of positive valences, and match well with the $\mathrm{PtO}_{2}$ reference with +IV valence. 
Table 1. EXAFS parameters for the specimens of the study, including: the coordination number N, the interatomic distance $\mathrm{R}$ between the absorber and backscatter atom, the mean-square disorder in the distance $\sigma^{2}$, and the energy correction term $\Delta \mathrm{E}$. A fixed amplitude factor $\mathrm{S}_{0}^{2}$ of unity was used for the fitting. The evaluated errors for $\mathrm{R}$ were \pm 0.009 for Pt-O and \pm 0.002 for Pt-Pt. The evaluated errors for $\sigma^{2}$ were \pm $0.4 \times 10^{-3}$ for both shells.

\begin{tabular}{|c|c|c|c|c|c|}
\hline Specimen & Shell & $\mathrm{N}$ & $\begin{array}{c}R \\
(\AA) \\
\end{array}$ & $\begin{array}{c}10^{3} \times \sigma^{2} \\
\left(\AA^{2}\right)\end{array}$ & $\begin{array}{l}\Delta \mathrm{E} \\
(\mathrm{eV})\end{array}$ \\
\hline Pt foil & $\mathrm{Pt}-\mathrm{Pt}$ & 12 & 2.81 & & \\
\hline $\mathrm{PtO}_{2}$ & $\begin{array}{l}\text { Pt-O } \\
\text { Pt-Pt }\end{array}$ & $\begin{array}{c}6 \\
12\end{array}$ & $\begin{array}{l}1.94 \\
3.17\end{array}$ & & \\
\hline WTI-TAPN & $\begin{array}{l}\text { Pt-N } \\
\text { Pt-N }\end{array}$ & $\begin{array}{l}4 \\
2\end{array}$ & $\begin{array}{l}2.04 \\
3.73\end{array}$ & & \\
\hline WTi-Pt2.5 & $\begin{array}{l}\mathrm{Pt}-\mathrm{O} \\
\mathrm{Pt}-\mathrm{Pt}\end{array}$ & $\begin{array}{l}3.1 \\
1.9 \\
\end{array}$ & $\begin{array}{l}1.89 \\
3.01\end{array}$ & $\begin{array}{l}4.0 \\
1.9\end{array}$ & $\begin{array}{l}-5.7 \\
-8.0\end{array}$ \\
\hline
\end{tabular}

Extended X-ray absorption fine structure (EXAFS) has been used to verify the atomically dispersed individual $\mathrm{Pt}$ atoms throughout the whole catalyst, for example, $\mathrm{Pt} 1 / \mathrm{FeOx},{ }^{37} \mathrm{Pt} / \mathrm{CeO}_{2},{ }^{38}$ and $\mathrm{Pt}$ support on Titanium Nitride. ${ }^{39}$ We provide the EXAFS data in the supplementary materials (Figure S10) and the Fourier transformed EXAFS oscillations in Figure 3d. The fitting parameters have been included in table 1 and details of the fitting have been included in Figure S11. The spectra are $\mathrm{k}^{3}$ weighted with a $\Delta \mathrm{k}$ range of $3-10 \AA^{-1}$. Metallic Pt is dominated by Pt-Pt coordination, characterized by the strong peak at $2.7 \AA$. In contrast, the Pt-Pt bond is missing in the $\mathrm{PtO}_{2}$ reference which instead shows predominantly Pt-O coordinated shells with a characteristic peak at $1.7 \AA$. In both the EXAFS for $W T i$-Pt2.5, as well as for $W T i-T A P N$, the dominating peak is located at $1.7 \AA$. The peak at $2.7 \AA$ is suppressed indicating the absence of metallic clusters. This observation suggests that the thermal treatment did not turn the Pt species into metallic particles, but rather that atomic dispersed $\mathrm{Pt}$ species on $\mathrm{TiO}_{2}$ were formed. 

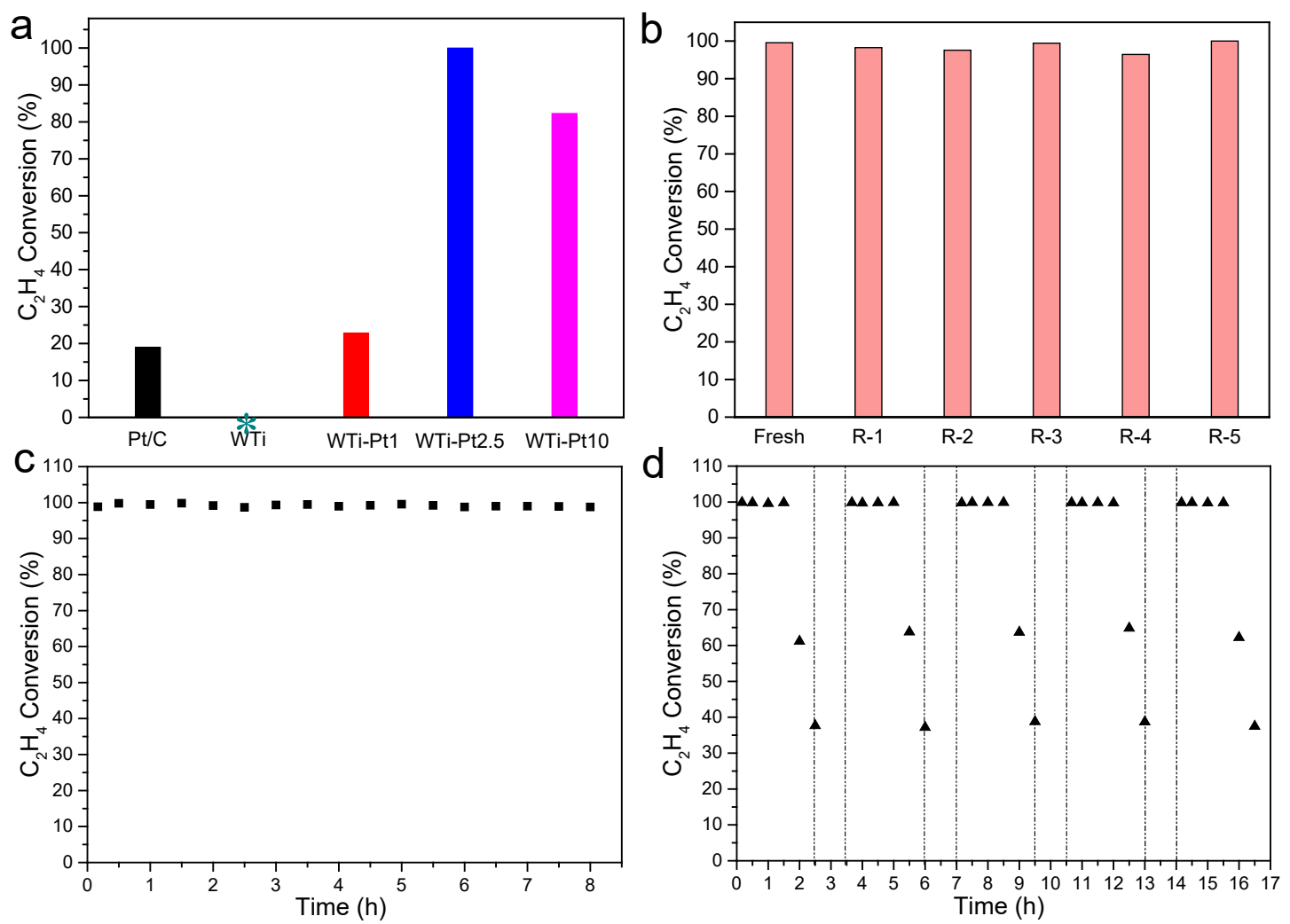

Figure 4. (a) Ethylene conversion over $W T i-\mathrm{Pt} X$ and $W T i(0.8 \mathrm{~g})$ at $0{ }^{\circ} \mathrm{C}$ in the batch reactor. The ethylene elimination over the commercialized Pt on carbon ( $0.53 \mathrm{mg}$, $1 \mathrm{wt}$ \% Pt loading) was provided for comparison; (b) catalysis performance of the re-fleshed WTi-Pt2.5 catalysts in the batch reactor. Ethylene decomposition and the durability of WTi-Pt2.5 at (c) $25^{\circ} \mathrm{C}$ and (d) $0{ }^{\circ} \mathrm{C}$. Reaction conditions in c and d: $\mathrm{C}_{2} \mathrm{H}_{4}: 80$ ppm; $\mathrm{O}_{2}: 20$ vol \%; $\mathrm{N}_{2}: 5$ vol \%; He balance; Flow rate: $10 \mathrm{~mL} / \mathrm{min}$.

We applied the hierarchically porous $W T i-\mathrm{Pt} X$ to catalyze the oxidation decomposition of ethylene in a batch reactor. Firstly, we tested the conversion capacity of the catalysts by exposing them to excessive ethylene in a 1.5 liter sealed flask at $0{ }^{\circ} \mathrm{C}$. The ethylene concentration was measured 1 min after the injection of pure ethylene and then subtracted from the constant ethylene concentration in order to deduce the conversion ratio. As shown in Figure 4a, WTi did not contribute to any ethylene concentration reduction, which indicates that neither the cellulose scaffold nor the $\mathrm{TiO}_{2} / \mathrm{Ce}$ xerogel can reduce the ethylene by either physical absorption or chemical conversion. In the presence of $\mathrm{Pt}, W T i-\mathrm{Pt} 10$ can reduce the ethylene concentration by $82.3 \%$ in $15 \mathrm{~min}$. The ethylene conversion rate increased to $100 \%$ in the presence of $W T i-\mathrm{Pt} 2.5$. The results indicate that the Pt elements deposited on the WTi support became more active and durable as their dispersion increased. However, this value decreased dramatically to about $22.9 \%$ in the presence of WTi-Pt1 because the catalyst could not provide enough active sites. For comparison, we also tested the 
ethylene conversion capacity of commercialized Pt on carbon. We used $0.53 \mathrm{mg}$ of the commercialized Pt on carbon (1 wt. \% Pt) to obtain the same amount of Pt loading as $0.8 \mathrm{~g}$ of the WTiPt2.5 the batch. The results demonstrated that commercialized Pt on carbon catalyst could only convert $19.0 \%$ ethylene. The mass activity was used for a reliable comparison, which accounts for the number of moles of ethylene conversion per mole of Pt per hour. The results demonstrate that WTi-Pt2.5 has a similar mass activity as WTi-Pt1, while WTi-Pt10 has the lowest mass activity (Table S2). Although the catalysts are highly active, they are still not durable after the exposure to a highly concentrated ethylene atmosphere. All of the catalysts are inactive after the first batch reaction. According to the ethylene oxidation mechanism proposed by Fukuoka et al., ${ }^{11}$ water is one of the products, which can accumulate on the surface of Pt atoms at zero degrees, and therefore, can insulate the Pt atoms from ethylene. We tested the reusability of WTi-Pt2.5. As shown in Figure $4 \mathrm{~b}$, after the refreshment at $150^{\circ} \mathrm{C}$ in the $\mathrm{N}_{2}$ atmosphere for $1 \mathrm{~h}, W T i$-Pt 2.5 can still eliminate ethylene completely. The refreshment experiment was repeated 6 times, and the ethylene conversion of WTi-Pt2.5 was almost constant. The results revealed that the ethylene conversion capacity could be recovered by removing the water molecules accumulated on the Pt surfaces. According to the previous study ${ }^{40}$ the ethylene decomposition over the catalyst occurs via the HCHO intermediate state. The reaction starts with the absorption of ethylene molecules on the Pt species. The ethylene molecules are sequentially oxygenized to the dioxide intermediately, which undergoes $\mathrm{C}$-C $\sigma$-bond cleavage to form $\mathrm{HCHO}$. The catalyst edge-effect ${ }^{41}$ and the surface-active oxygen species ${ }^{10,42}$ have significant influences on the $\mathrm{C}-\mathrm{C} \sigma$-bond cleavage by reducing the activation energy. The $\mathrm{HCHO}$ is further oxidized to $\mathrm{CO}$, and then to $\mathrm{CO}_{2}$, whereas $\mathrm{H}$ atoms generated from $\mathrm{HCHO}$ will react with $\mathrm{O}$ atoms to form $\mathrm{H}_{2} \mathrm{O}$ molecules. But Part of $\mathrm{HCHO}$ can be oxidized into $\mathrm{HCOOH}$ as a form of formic acid and formate species. ${ }^{11}$ Miyazaki's study indicates that the $\mathrm{CO}$ oxidation step is the ratedetermining step in the complete ethylene oxidation. ${ }^{41}$ The $\mathrm{H}_{2} \mathrm{O}$ molecules adsorbing onto the active sites is the main reason that results in the deactivation. ${ }^{43}$ 
A more practical study of the catalytic performance of WTi and WTi-Pt2.5 was carried out in a continuous reactor with trace ethylene $(80 \mathrm{ppm})$ at $25^{\circ} \mathrm{C}$ and $0{ }^{\circ} \mathrm{C}$, respectively. The results indicate that WTi cannot absorb or decompose ethylene, while the conversion of 80 ppm ethylene was about $100 \%$ at $25^{\circ} \mathrm{C}$ in the presence of WTi-Pt2.5 (Figure 4c). The complete conversion can last for at least 8 hours, which reveals a great potential application for the preservation of fresh food during warehouse storage. We further studied the low temperature $\left(0^{\circ} \mathrm{C}\right)$ ethylene decomposition performance of $W T i-\mathrm{Pt} 2.5$. As demonstrated in Figure 4d, the conversion rate kept at almost $100 \%$ in the first $1.5 \mathrm{~h}$. Afterward, it decreased to $60 \%$ in 2 hours and then about $38 \%$ in 2.5 hours. The decrease in the conversion rate was due to the accumulation of water at $0{ }^{\circ} \mathrm{C}$, which covered the $\mathrm{Pt}$ atoms. The catalysts were reactivated by heat treatment at $150{ }^{\circ} \mathrm{C}$ with $\mathrm{N}_{2}$ flow for one hour. An equal catalytic performance could be achieved even after recycling for five times.

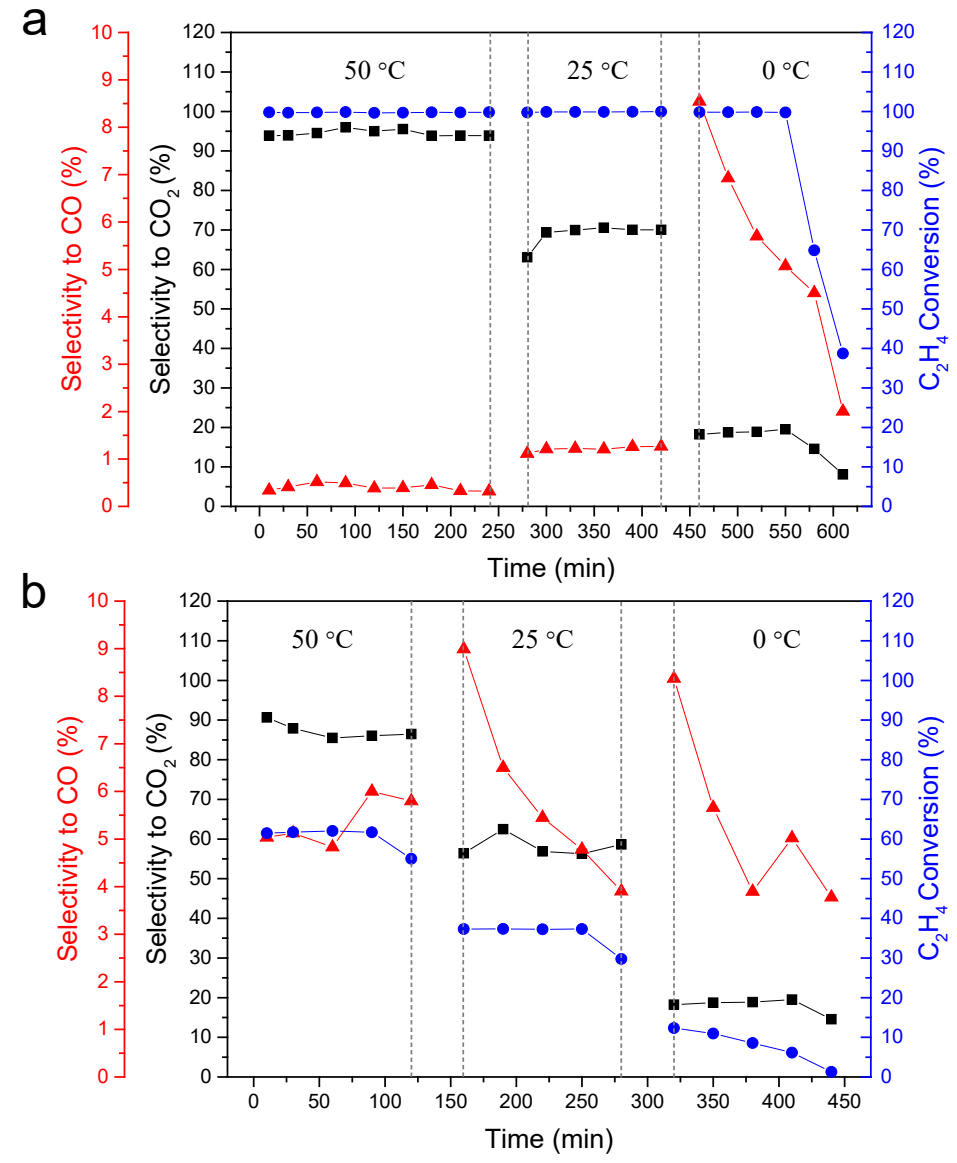

Figure 5. Ethylene conversion (blue), $\mathrm{CO}_{2}$ selectivity (black) and $\mathrm{CO}$ selectivity (red) with time-on-steam at $50{ }^{\circ} \mathrm{C}, 25{ }^{\circ} \mathrm{C}$ and $0{ }^{\circ} \mathrm{C}$ over (a) WTi-Pt2.5 and (b) commercialized Pt on carbon ( 1 wt. \% Pt loading). Reaction conditions: WTi-Pt2.5 mass $0.8 \mathrm{~g}$; carbon support Pt mass $0.53 \mathrm{mg} ; \mathrm{C}_{2} \mathrm{H}_{4}: 80 \mathrm{ppm} ; \mathrm{O}_{2}: 20$ vol \%; $\mathrm{N}_{2}: 5$ vol \%; He balance; Flow rate: $10 \mathrm{~mL} / \mathrm{min}$. 
We further demonstrate the selective catalytic conversion of ethylene to $\mathrm{CO}_{2}$ and $\mathrm{CO}$ over WTiPt2.5 at different temperatures with the commercialized Pt on Carbon as a comparison. As shown in Figure 5a, a full ethylene conversion with $95 \% \mathrm{CO}_{2}$ selectivity and $0.4 \% \mathrm{CO}$ over WTi-Pt2.5 was observed at a reaction temperature of $50^{\circ} \mathrm{C}$. Although a full ethylene conversion can be maintained as the reaction temperature was reduced to $25^{\circ} \mathrm{C}$, the $\mathrm{CO}_{2}$ selectivity decreased to $70 \%$ while the CO selectivity increased to $1.2 \%$. Part of the ethylene may converse to formic acid or formate species, which was not detectable in our gas chromatography system, via incomplete oxidation according to previous report. ${ }^{11}$ As the reaction temperature was further reduced to $0{ }^{\circ} \mathrm{C}$, ethylene conversion ratio could be preserved at $100 \%$ in the first $90 \mathrm{~min}$ and then dropped dramatically. The similar trend was observed in $\mathrm{CO}_{2}$ selectivity, which kept at $19 \%$ in the beginning and then decreased after 90 min on stream. The CO selectivity declined continuously from $8.5 \%$ to $1.5 \%$ in $150 \mathrm{~min}$ at $0{ }^{\circ} \mathrm{C}$. On the other hand, the ethylene conversion ratio was only $\sim 60 \%$ at 50 ${ }^{\circ} \mathrm{C}$ over the commercialized $\mathrm{Pt}$ on carbon (Figure $5 \mathrm{~b}$ ). The $\mathrm{CO}_{2}$ selectivity is lower $(\sim 85 \%)$ while the CO selectivity is higher $(\sim 5.5 \%)$ compared with WTi-Pt2.5 under the sample condition. Both the ethylene conversion ratio and $\mathrm{CO}_{2}$ selectivity declined continuously as the reaction temperature decreased. The results demonstrate that WTi-Pt2.5 has superior catalytic performance for ethylene oxidation compared with the commercialized Pt on carbon catalysts. A comparison of the ethylene conversion activities of WTi-Pt2.5 with the previous reports demonstrates that our catalysts have a superior performance (Table S3). 

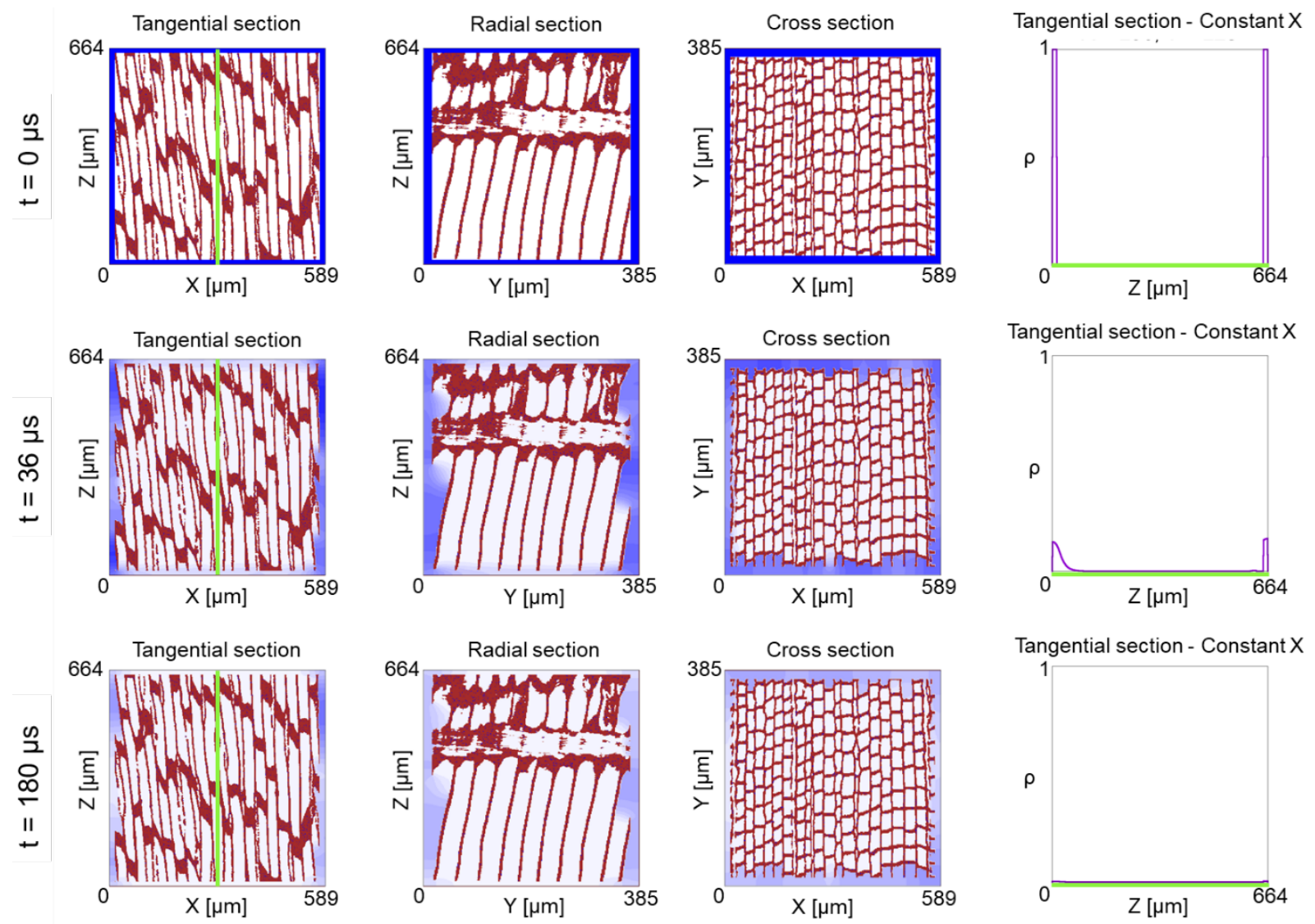

Figure 6. Transport of ethylene inside a cellulose scaffold at $0{ }^{\circ} \mathrm{C}$ in the presence of $20 \%$ Platinum along the cell wall surface. In the first three columns we show the different sections: transverse, radial and cross (from left to right). The wood cellulose scaffold (WTi) is in red and the ethylene concentration is in different shades of blue. In the fourth column we show the Z-dependence of the density at fixed $\mathrm{X}$ and $\mathrm{Y}$ values. Along the rows, we show the snapshots of the evolution of the ethylene transport at three different times. The first row shows the initial condition, where the ethylene concentration is normalized to one in the space between the container and the sample and zero inside the sample. The second and third rows show the state after 20 and 100 time steps respectively. $\mathrm{X}, \mathrm{Y}$ and $\mathrm{Z}$ are expressed in terms of the number of voxels and the density $\rho$ is in arbitrary units.

The effect of the porosity derived from wood on ethylene transport and decomposition was studied by a complementary computer simulation. We considered a system composed of a platinumenriched WTi sample sealed inside an impermeable container. The simulation was initialized by adding a uniform mixture of air and ethylene to the space between the sample and the container walls. At the start of the simulation, the pores inside the WTi structure were assumed to contain only air. Due to the absence of external driving forces and currents, we assumed that the transport of ethylene inside the sample was purely diffusive. We therefore used the lattice Boltzmann model 
to solve the diffusion equation (described in detail in Section 4 of the SI), which has been proven to be an accurate and efficient tool for handling complex geometries, such as wood structures. ${ }^{44-46}$ The evolution of the ethylene density was simulated with the diffusion equation (Eq 1) on the sample shown in Figure 6 (see also Figure S8).

$$
\partial \rho / \partial t=D \nabla^{2} \rho \quad \text { Eq. } 1
$$

In Eq $1, \rho$ is the local ethylene density and $D$ is the local diffusivity of ethylene in air. We discretized the sample under study into voxels containing the cellulose and $\mathrm{TiO}_{2}$ composite (red), whose domain was obtained from the segmentation of the cell wall structure from the X-ray tomogram, the air inside the pores of the cellulose structure (white), platinum atoms on the cell wall surface (cannot be seen in the figure) or a mixture of air and ethylene (blue shade whose intensity depends on the concentration of ethylene). With the help of the lattice Boltzmann model we simulated the diffusion of ethylene gas, together with its decomposition in the presence of the platinum catalyst inside the complex structure of WTi. The local diffusivity, the local ethylene decomposition rate and the platinum concentration are the input parameters of the model. Once they were assigned, we could simulate the evolution of the ethylene density inside the complex structure. The simulation was divided into two categories, one at high temperature $\left(25^{\circ} \mathrm{C}\right)$ and one at low temperature $\left(0^{\circ} \mathrm{C}\right)$. At low temperatures, we assumed that ethylene decomposition caused water to condense over the platinum-enriched regions, thus causing a cessation in the reaction between ethylene and oxygen.

In Figure 6 we show the distribution of ethylene inside a sample that was kept at low temperature, at three different time instances. The shades of blue represent the concentration (density) of the ethylene present in each voxel. A quantitative result of the simulation is shown in Figure 7. It shows how the ethylene density is distributed along the intersection between the tangential and radial plane at four different time instances. We explored three different cases: a sample without platinum atoms and samples with platinum atoms at low and high temperatures. In the former case (sample without platinum) the total ethylene mass is conserved whilst in the latter two cases the ethylene mass was reduced over time due to decomposition. Nevertheless, in all three cases the ethylene gas eventually reached the centre of the sample. This is indicated by the non-zero value of the ethylene density across the entire middle section of the sample. However, in the presence of platinum atoms, the amount of ethylene that reached the inner part of the sample was dramatically reduced, by many orders of magnitude, implying that most of it was decomposed closer to the surface. Furthermore, our simulation indicates that at high temperatures, in the absence of water condensation, the total 
mass of the ethylene decomposed exponentially, at a constant rate and much faster than at the low temperatures in which case the decomposition was no longer exponential (Figure S15).
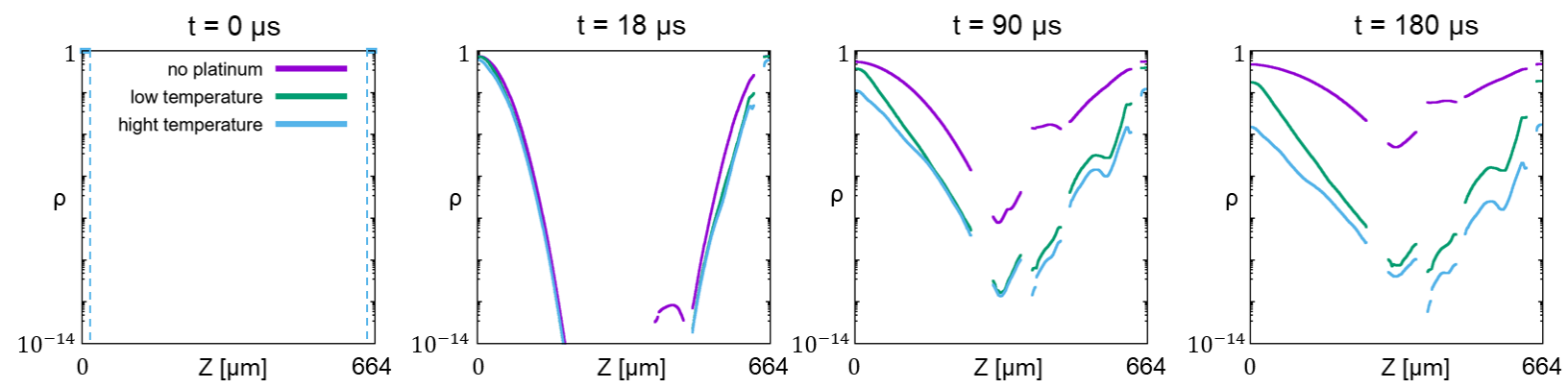

Figure 7. Evolution of ethylene concentration over time along the line representing the intersection between the tangential and radial section (green line in Figure 6).

\section{Conclusion}

In summary, we used the hierarchically porous structure of wood as a scaffold to template the cellulose and $\mathrm{TiO}_{2} / \mathrm{Ce}$ xerogel composite, which operates as the ideal support for catalysts. The low heat treatment temperature for the auto-reduction of tetraammineplatinum(II) nitrate to $\operatorname{Pt}(0)$ as well as the strong interaction between $\mathrm{TiO}_{2} / \mathrm{Ce}$ xerogel and the reduced $\mathrm{Pt}$ species resulted in atomically dispersed $\mathrm{Pt}$ active species. The lack of metallicity in the X-ray fine structure spectra suggests the absence of Pt clustering in bulk. Slight clustering may be present at the surface where there is increased accumulation of Pt according to the XPS result. We show with this work the potential practical application of the complex structure derived from wood as a catalyst support for ethylene conversion. The ethylene $(80 \mathrm{ppm})$ conversion in WTi-Pt2.5 with a Pt concentration of $6.58 \mathrm{ppm}$ can reach $100 \%$ at $25^{\circ} \mathrm{C}$. This excellent ethylene conversion efficiency at room temperature may be due to the formation of atomically dispersed Pt species and the high surface area provided by the hierarchically porous wood. This work shows a way of manufacturing multifunctional materials with complex structures by the combination of controllable chemical synthesis with a nature-designed scaffold. The hierarchically complex structure can provide sufficient surface area for a catalytic chemical reaction but also eliminate the negative effects of using nanopowder in environmental catalysis. 


\section{Materials and methods}

Fabrication of wood cellulose and $\mathrm{TiO}_{2} / \mathrm{Ce}$ xerogel hybrid materials (WTi): Norway spruce (Picea abies) wood was used as a raw material for the preparation of hierarchical porous wood cellulose scaffolds via delignification. The wood was cut into a cube with a dimension of $10 \mathrm{~mm} \times$ $10 \mathrm{~mm} \times 5 \mathrm{~mm}$ in radial $\times$ tangential $\times$ longitudinal directions by a saw. The delignification was carried out according to the method reported by Deshpande et al. and further by Segmehl and Frey. ${ }^{23,24,28}$ Typically, ten pieces of wood were placed into a beaker, where $25 \mathrm{~mL}$ acetic acid (>99.8\%, Sigma-Aldrich Chemie) and $25 \mathrm{~mL}$ hydrogen peroxide solution (34\%, VWR Intentional AG) were added. The beaker was then sealed with paraffin film and heated in an oil bath at $60{ }^{\circ} \mathrm{C}$ for $48 \mathrm{~h}$. After this maceration treatment, the wood cubes were washed eight times with distilled water to remove leached out lignin and hemicelluloses. The solvent exchange was carried to transfer the cellulose scaffolds into isopropanol (99\%, Thommen-Furler AG). The precursor solution for the condensation of $\mathrm{TiO}_{2} / \mathrm{Ce}$ Xerogel was prepared by dissolving $1.5 \mathrm{~mL} \mathrm{Ammonium} \mathrm{Ce-}$ rium(IV) Nitrate $\left(\left(\mathrm{NH}_{4}\right)_{2} \mathrm{Ce}\left(\mathrm{NO}_{3}\right)_{6}, \geq 98 \%\right.$, Sigma-Aldrich Chemie) into isopropanol solution followed by the addition of Titanium(IV) Isopropoxide (97\%, Sigma-Aldrich Chemie) with a volume ratio of 1:10 to the isopropanol solution. WTi was prepared by adding $50 \mathrm{~mL}$ of the precursor solution into the cellulose scaffold. The beaker was stored at room temperature in ambient conditions. WTi was formed in about two weeks after the evaporation of isopropanol.

Catalyst preparation: Platinum precursor solution was prepared by dissolving $1 \mathrm{~g}$ of tetraammineplatinum(II) nitrate $\left(T A P N, \operatorname{Pt}\left(\mathrm{NH}_{3}\right)_{4}\left(\mathrm{NO}_{3}\right)_{2}, \geq 50.0 \%\right.$ Pt basis, Sigma-Aldrich Chemie) in 250 $\mathrm{mL}$ of distilled water, in which the platinum ion concentration was about $10.33 \mathrm{mM}$. The platinum precursor solution with a volume of $10 \mathrm{~mL}, 2.5 \mathrm{~mL}$, and $1 \mathrm{~mL}$ was added into three distinct glass vials, respectively, followed by further dilution with distilled water to $30 \mathrm{~mL}$ for each vial. In each glass vial, we added five pieces of WTi. Vacuum impregnation (three cycles, 5 min for each cycle) was applied to promote the penetration of the precursor solution. The WTi were kept in the precursor solution for 24 hours before being taken out for heat treatment at $250^{\circ} \mathrm{C}$ for 2 hours in a tube furnace with an atmosphere of 5\% Hydrogen and 95\% Nitrogen. The samples were named as $W T i$ Pt $X, X$ is equal to $10,2.5$ or 1 for the samples treated with the platinum precursor solution with a volume of $10 \mathrm{~mL}, 2.5 \mathrm{~mL}$ or $1 \mathrm{~mL}$, respectively.

Catalytic Decomposition of Ethylene: Five pieces of the $W T i-\mathrm{Pt} X$ were put into a one-liter twoneck round-bottom flask. Ethylene ( $\geq 99.9 \%$, PanGas) was injected into the flask to create an atmosphere with an ethylene concentration of around $2600 \mathrm{ppm}$. Atmosphere homogenization took 
$1 \mathrm{~min}$, after which the first measurement was carried out by taking $1 \mathrm{~mL}$ of the gas from the flask and injecting it into the Gas Chromatograph (GC). The second and third measurements were carried out after $10 \mathrm{~min}$ and $30 \mathrm{~min}$, respectively. The amount of ethylene converted by the catalysts was calculated by subtracting the concentration of ethylene measured after 1 min with that measured after $30 \mathrm{~min}$. The catalyst refreshing was carried out by storing $W T i-\mathrm{Pt} X$ into the furnace at $150{ }^{\circ} \mathrm{C}$ for one hour in a Nitrogen atmosphere. The same procedure as above was used to assess the performance of the refreshed catalysts. The refreshing experiment was repeated up to five cycles. The catalytic performance for low concentration ethylene decomposition was assessed by passing a mixture of $80 \mathrm{ppm}$ ethylene, $20 \mathrm{vol} \%$ oxygen, $5 \mathrm{vol} \% \mathrm{~N}_{2}$ balanced by He through a glass tube containing $0.8 \mathrm{~g}$ WTi-Pt2.5. The gas compounds were determined by on-line gas chromatography (SRI Instruments). All of the catalytic performances were assessed at $25^{\circ} \mathrm{C}$ and $0{ }^{\circ} \mathrm{C}$, respectively. Characterization: the structure of $W T i-\mathrm{Pt} X$ was investigated in 3D using X-ray tomography performed at Empa's Center for X-ray Analytics. We used X-ray tomography and a respective 3D image analysis workflow to semi-quantitatively characterize the part of the pore space of the woodbased scaffold resolved by the performed tomography measurements, the spatial resolution being approximately of $0.9-1 \mu \mathrm{m}$. In addition, by the same 3D image analysis workflow, we produced a 3D geometric model of the wood cell structure. Such a 3D geometric model of the cell wall provided a realistic geometrical domain for the gas transport modeling by the lattice Boltzmann numerical simulations described below and in Section 4 of the Supporting Information. Section 1 of the Supporting Information also contains information about the tomography measurements and the respective 3D image analysis. Nitrogen adsorption and desorption were conducted using a Micromeritics TriStar II 3020 apparatus to characterize the porous texture properties, including BETspecific surface area, total pore volume, and pore size distribution. In this study, about $0.5-2 \mathrm{~g}$ samples were used for the tests depending on the estimated surface area. For the purpose of comparison, all tests used the same degassing level in which the samples were vacuumed at a pressure below $20 \mu \mathrm{m} \mathrm{Hg}$ and a temperature of $65^{\circ} \mathrm{C}$ for 20 hours. The measurement started from 0.01 relative pressure and increased to 0.99 to get the adsorption curve and then decreased to 0.01 to obtain the desorption curve. BET surface area was calculated based on data from adsorption between 0.05 and 0.3 relative pressure. The pore size distribution was calculated by the BarrettJoyner-Halenda $(\mathrm{BJH})$ method using the adsorption curve.

The Pt content in the catalyst was analyzed using Inductively Coupled Plasma Optical Emission Spectroscopy (ICP-OES, Horiba Ultra 2 instrument equipped with photomultiplier tube detection). 
For this purpose, $W T i-\mathrm{Pt} X$ were first grounded into powder, and then they were quantitatively dissolved in aqua regia. The phase of the catalyst was analyzed by X-ray powder diffraction (XRD) in Bragg-Brentano mode and $\theta-2 \theta$ geometry with $\mathrm{Cu}-\mathrm{K} \alpha$ radiation (PANalytical, Almelo, The Netherlands). The specific surface area of the composites was measured using a BET nitrogen physisorption device (Micromeritics Tristar II 3020). The TEM specimens were prepared by embedding the sample with resin (Spurr Low Viscosity Embedding Kit), followed by cutting a transverse section of about $150 \mathrm{~nm}$ in thickness with a Reicher-Jung Ultracut Ultramicrotome using a diamond knife. The section was mounted on a lacey carbon film on Copper TEM grids. High angle annular dark field scanning transmission electron microscopy (HAADF-STEM) and energy dispersive X-ray spectrometry (EDS) studies were carried out at ScopeM ETHZ with a FEI Talos operated at $200 \mathrm{kV}$. X-ray Photoelectron Spectroscopy (XPS) was performed using an X-ray photoemission spectrometer (Physical Electronics, Quantum 2000) with monochromatic Al Ka radiation $(\mathrm{h} v=1486.7 \mathrm{eV})$. X-ray Absorption Near Edge Structure (XANES) and Extended X-ray Absorption Fine Structure (EXAFS) spectroscopy were obtained at the microXAS beamline of the Swiss Light Source by the Paul Scherrer Institute, Villigen, Switzerland.

\section{Acknowledgment}

This research was financially supported by the ETH Career Seed Grant (SEED-14 17-1). We thank Prof. Ingo Burgert (ETH) for the discussion and other supports. We thank Anja Huch (Empa) and Fabian Gramm (ScopeM of ETH) for thier help in TEM sample preparation and imaging, and Rolf Kaufmann (Empa) for the support with the X-ray tomography measurements. We also thank Miller Mendoza (ETH) for his help with the lattice Boltzmann method. Part of the 3D image analysis of the X-ray tomogram was performed by the use of the Empa Platform for Image Analysis (https://www.empa.ch/web/s499/3d-image-analysis-simulation) maintained at Empa's Center for X-ray Analytics.

Supporting Information Available: The supporting information includes details about the X-ray Tomography analysis, modelling details of the gas transport process and the materials characterization results. This material is available free of charge via the Internet at http://pubs.acs.org.

\section{Reference}

1. Saltveit, M. E., Effect of Ethylene on Quality of Fresh Fruits and Vegetables. Postharvest Biol. Technol. 1999, 15, 279-292. 
2. Vilela, C.; Kurek, M.; Hayouka, Z.; Röcker, B.; Yildirim, S.; Antunes, M. D. C.; Nilsen-Nygaard, J.; Pettersen, M. K.; Freire, C. S. R., A Concise Guide to Active Agents for Active Food Packaging. Trends in Food Sci. Technol. 2018, 80, 212-222.

3. Keller, N.; Ducamp, M.-N.; Robert, D.; Keller, V., Ethylene Removal and Fresh Product Storage: A Challenge at the Frontiers of Chemistry. Toward an Approach by Photocatalytic Oxidation. Chem. Rev. 2013, 113, 5029-5070.

4. Westrich, T. A.; Dahlberg, K. A.; Kaviany, M.; Schwank, J. W., High-Temperature Photocatalytic Ethylene Oxidation over $\mathrm{TiO}_{2}$. J. Phys. Chem. C 2011, 115, 16537-16543.

5. Bhattacharyya, K.; Varma, S.; Tripathi, A. K.; Bharadwaj, S. R.; Tyagi, A. K., Mechanistic Insight by In Situ FTIR for the Gas Phase Photo-Oxidation of Ethylene by V-Doped Titania and Nano Titania. $J$. Phys. Chem. B 2009, 113, 5917-5928.

6. Bhattacharyya, K.; Varma, S.; Tripathi, A. K.; Vinu, A.; Tyagi, A. K., Gas-Phase Photooxidation of Alkenes by V-Doped $\mathrm{TiO}_{2}-\mathrm{MCM}-41$ : Mechanistic Insights of Ethylene Photooxidation and Understanding the Structure-Activity Correlation. Chem. - Eur. J. 2011, 17, 12310-12325.

7. Pan, X.; Chen, X.; Yi, Z., Defective, Porous $\mathrm{TiO}_{2}$ Nanosheets with Pt Decoration as An Efficient Photocatalyst for Ethylene Oxidation Synthesized by $\mathrm{A}_{3} \mathrm{~N}_{4}$ Templating Method. ACS Appl. Mater. Interfaces 2016, 8, 10104-10108.

8. Du, J.; Yang, M.; Wang, J., Comparative Study of the Interaction of $\mathrm{O}_{2}$ and $\mathrm{C}_{2} \mathrm{H}_{4}$ with Small Vanadium Clusters from Density Functional Theory. J. Phys. Chem. A 2011, 115, 10259-10265.

9. $\quad$ Isaifan, R. J.; Penwell, W. D.; Filizzola, J. O. C.; Giorgi, J. B.; Baranova, E. A., Promotion of Pt Nanoparticles by Lattice Oxygen in $\mathrm{SmFeO}_{3}$ Perovskite Group for Carbon Monoxide and Ethylene Oxidation. Top. in Catal. 2015, 58, 1218-1227.

10. Ma, C. Y.; Mu, Z.; Li, J. J.; Jin, Y. G.; Cheng, J.; Lu, G. Q.; Hao, Z. P.; Qiao, S. Z., Mesoporous $\mathrm{Co}_{3} \mathrm{O}_{4}$ and $\mathrm{Au} / \mathrm{Co}_{3} \mathrm{O}_{4}$ Catalysts for Low-Temperature Oxidation of Trace Ethylene. J. Am. Chem. Soc. 2010, 132, 2608-2613.

11. Jiang, C.; Hara, K.; Fukuoka, A., Low-Temperature Oxidation of Ethylene over Platinum Nanoparticles Supported on Mesoporous Silica. Angew. Chem., Int. Ed. 2013, 52, 6265-6268.

12. Dole, H. A. E.; Baranova, E. A., Ethylene Oxidation in an Oxygen-Deficient Environment: Why Ceria is an Active Support? ChemCatChem 2016, 8, 1977-1986.

13. Nie, L.; Zheng, Y.; Yu, J., Efficient Decomposition of Formaldehyde at Room Temperature over Pt/Honeycomb Ceramics with Ultra-Low Pt Content. Dalton Trans. 2014, 43, 12935-12942.

14. Kataoka, S.; Tompkins, D. T.; Zeltner, W. A.; Anderson, M. A., Photocatalytic Oxidation in the Presence of Microwave Irradiation: Observations with Ethylene and Water. J. Photochem. Photobiol., A 2002, 148, 323-330.

15. Zorn, M. E.; Tompkins, D. T.; Zeltner, W. A.; Anderson, M. A., Catalytic and Photocatalytic Oxidation of Ethylene on Titania-Based Thin-Films. Environ. Sci. Technol. 2000, 34, 5206-5210.

16. Mao, L.-B.; Gao, H.-L.; Yao, H.-B.; Liu, L.; Cölfen, H.; Liu, G.; Chen, S.-M.; Li, S.-K.; Yan, Y.X.; Liu, Y.-Y.; Yu, S.-H., Synthetic Nacre by Predesigned Matrix-Directed Mineralization. Science 2016, 354, 107-110.

17. Wegst, U. G. K.; Bai, H.; Saiz, E.; Tomsia, A. P.; Ritchie, R. O., Bioinspired Structural Materials. Nat. Mater. 2014, 14, 23-36.

18. Berglund, L. A.; Burgert, I., Bioinspired Wood Nanotechnology for Functional Materials. Adv. Mater. 2018, 30, 1704285.

19. Chen, L.-H.; Li, X.-Y.; Rooke, J. C.; Zhang, Y.-H.; Yang, X.-Y.; Tang, Y.; Xiao, F.-S.; Su, B.-L., Hierarchically Structured Zeolites: Synthesis, Mass Transport Properties and Applications. J. Mater. Chem. 2012, 22, 17381-17403.

20. Yang, X.-Y.; Chen, L.-H.; Li, Y.; Rooke, J. C.; Sanchez, C.; Su, B.-L., Hierarchically Porous Materials: Synthesis Strategies and Structure Design. Chem. Soc. Rev. 2017, 46, 481-558.

21. Guo, H.; Fuchs, P.; Casdorff, K.; Michen, B.; Chanana, M.; Hagendorfer, H.; Romanyuk, Y. E.; Burgert, I., Bio-Inspired Superhydrophobic and Omniphobic Wood Surfaces. Adv. Mater. Interfaces 2017, 4, 1600289. 
22. SjÖStrÖM, E., Chapter 1 - The Structure of Wood. In Wood Chemistry (Second Edition), Academic Press: San Diego, 1993; pp 1-20.

23. Deshpande, A. S.; Burgert, I.; Paris, O., Hierarchically Structured Ceramics by High-Precision Nanoparticle Casting of Wood. Small 2006, 2, 994-998.

24. Frey, M.; Widner, D.; Segmehl, J. S.; Casdorff, K.; Keplinger, T.; Burgert, I., Delignified and Densified Cellulose Bulk Materials with Excellent Tensile Properties for Sustainable Engineering. ACS Appl. Mater. Interfaces 2018, 10, 5030-5037.

25. Wang, J.; Li, Z.; Wu, Y.; Li, Y., Fabrication of Single-Atom Catalysts with Precise Structure and High Metal Loading. Adv. Mater. 2018, 30, 1801649.

26. Olsson, R. T.; Azizi Samir, M. A. S.; Salazar Alvarez, G.; BelovaL; StromV; Berglund, L. A.; IkkalaO; NoguesJ; Gedde, U. W., Making Flexible Magnetic Aerogels and Stiff Magnetic Nanopaper Using Cellulose Nanofibrils as Templates. Nat. Nanotechnol. 2010, 5, 584-588.

27. Nonappa; Ikkala, O., Hydrogen Bonding Directed Colloidal Self-Assembly of Nanoparticles into 2D Crystals, Capsids, and Supracolloidal Assemblies. Adv. Funct. Mater. 2018, 28, 1704328.

28. Segmehl, J. S.; Studer, V.; Keplinger, T.; Burgert, I., Characterization of Wood Derived Hierarchical Cellulose Scaffolds for Multifunctional Applications. Materials 2018, 11, 517.

29. Guo, H.; Klose, D.; Hou, Y.; Jeschke, G.; Burgert, I., Highly Efficient UV Protection of the Biomaterial Wood by A Transparent $\mathrm{TiO}_{2} /$ Ce Xerogel. ACS Appl. Mater. Interfaces 2017, 9, 39040-39047.

30. Chen, Y.; Ji, S.; Sun, W.; Chen, W.; Dong, J.; Wen, J.; Zhang, J.; Li, Z.; Zheng, L.; Chen, C.; Peng, Q.; Wang, D.; Li, Y., Discovering Partially Charged Single-Atom Pt for Enhanced Anti-Markovnikov Alkene Hydrosilylation. J. Am. Chem. Soc. 2018, 140, 7407-7410.

31. Oudenhuijzen, M. K.; Kooyman, P. J.; Tappel, B.; van Bokhoven, J. A.; Koningsberger, D. C., Understanding the Influence of the Pretreatment Procedure on Platinum Particle Size and Particle-Size Distribution for $\mathrm{SiO} 2$ Impregnated with $\left[\mathrm{Pt}^{2+}\left(\mathrm{NH}_{3}\right)_{4}\right]\left(\mathrm{NO}^{3-}\right)_{2}$ : A Combination of HRTEM, Mass Spectrometry, and Quick EXAFS. J. Catal. 2002, 205, 135-146.

32. Liu, P.; Zhao, Y.; Qin, R.; Mo, S.; Chen, G.; Gu, L.; Chevrier, D. M.; Zhang, P.; Guo, Q.; Zang, D., Photochemical Route for Synthesizing Atomically Dispersed Palladium Catalysts. Science 2016, 352, 797 800 .

33. Sing, K. S. W., Reporting Physisorption Data for Gas/Solid Systems with Special Reference to the Determination of Surface Area and Porosity. IUPAC Commission on Colloid and Surface Chemistry Including Catalysis. Pure Appl. Chem. 1985, 57, 603-619.

34. Dückers, K.; Bonzel, H. P., Core and Valence Level Spectroscopy with Y M $\zeta$ Radiation: CO and K on (110) Surfaces of Ir, Pt and Au. Surf. Sci. 1989, 213, 25-48.

35. Seuser, G. S.; Banerjee, R.; Metavarayuth, K.; Brandt, A. J.; Maddumapatabandi, T. D.; Karakalos, S.; Lin, Y.; Regalbuto, J. R.; Chen, D. A., Understanding Uptake of Pt Precursors During Strong Electrostatic Adsorption on Single-Crystal Carbon Surfaces. Top. Catal.s 2018, 61, 379-388.

36. Fujiwara, K.; Müller, U.; Pratsinis, S. E., Pd Subnano-Clusters on $\mathrm{TiO}_{2}$ for Solar-Light Removal of NO. ACS Catal. 2016, 6, 1887-1893.

37. Qiao, B.; Wang, A.; Yang, X.; Allard, L. F.; Jiang, Z.; Cui, Y.; Liu, J.; Li, J.; Zhang, T., SingleAtom Catalysis of CO Oxidation Using Pt1/FeOx. Nat. Chem. 2011, 3, 634.

38. Nie, L.; Mei, D.; Xiong, H.; Peng, B.; Ren, Z.; Hernandez, X. I. P.; DeLaRiva, A.; Wang, M.; Engelhard, M. H.; Kovarik, L.; Datye, A. K.; Wang, Y., Activation of Surface Lattice Oxygen in SingleAtom $\mathrm{Pt} / \mathrm{CeO}_{2}$ for Low-Temperature CO Oxidation. Science 2017, 358, 1419.

39. Yang, S.; Kim, J.; Tak, Y. J.; Soon, A.; Lee, H., Single-Atom Catalyst of Platinum Supported on Titanium Nitride for Selective Electrochemical Reactions. Angew. Chem., Int. Ed. 2016, 55, 2058-2062.

40. Satter, S. S.; Yokoya, T.; Hirayama, J.; Nakajima, K.; Fukuoka, A., Oxidation of Trace Ethylene at $0{ }^{\circ} \mathrm{C}$ over Platinum Nanoparticles Supported on Silica. ACS Sustainable Chem. Eng. 2018, 6, 11480-11486. 41. Miyazaki, R.; Nakatani, N.; Levchenko, S. V.; Yokoya, T.; Nakajima, K.; Hara, K.; Fukuoka, A.; Hasegawa, J.-y., DFT Mechanistic Study on the Complete Oxidation of Ethylene by the Silica-Supported Pt Catalyst: $\mathrm{C}=\mathrm{C}$ Activation via the Ethylene Dioxide Intermediate. J. Phys. Chem. C 2019, 123, 1270612715. 
42. Yang, H.; Ma, C.; Wang, G.; Sun, Y.; Cheng, J.; Zhang, Z.; Zhang, X.; Hao, Z., Fluorine-Enhanced Pt/ZSM-5 Catalysts for Low-Temperature Oxidation of Ethylene. Catal. Sci. Technol. 2018, 8, 1988-1996. 43. Yang, H.; Ma, C.; Zhang, X.; Li, Y.; Cheng, J.; Hao, Z., Understanding the Active Sites of $\mathrm{Ag} /$ Zeolites and Deactivation Mechanism of Ethylene Catalytic Oxidation at Room Temperature. ACS Catal. 2018, 8, 1248-1258.

44. Wolf-Gladrow, D., A Lattice Boltzmann Equation for Diffusion. J. Stat. Phys. 1995, 79, 1023-1032. 45. Mendoza, M.; Wittel, F. K.; Herrmann, H. J., Simulation of Flow of Mixtures through Anisotropic Porous Media Using A Lattice Boltzmann Model. Eur. Phys. J. E 2010, 32, 339-348.

46. Guo, H.; Luković, M.; Mendoza, M.; Schlepütz, C. M.; Griffa, M.; Xu, B.; Gaan, S.; Herrmann, H.; Burgert, I., Bioinspired Struvite Mineralization for Fire-Resistant Wood. ACS Appl. Mater. Interfaces 2019, $11,5427-5434$. 


\section{TOC}

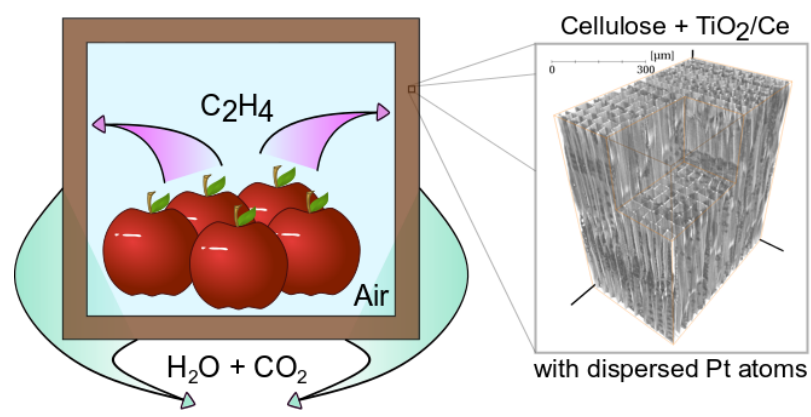

